the psychosocial environment, the organisation and logistics was affected, making the workflow more inefficient. The closeness to the hospital was appreciated by all groups. The staff perceived the managers to be both near and far away. Contacts with managers seated in an open workplace became more visible, while managers seated in specific head departments were not easily accessible. The hierarchy of the organisation became more visible in the open design office.

Conclusion An important contribution from this evaluation is to learn from what works for the staff and find success factors for a good work environment in the open workplaces. For example, allocate time to educate staff in new methods and approaches needed in the open workplace, seat managers together with staff to increase flow of information and to strengthen relations, promote flexibility by modern information technology and continuously evaluate and adjust to ensure that offices are suited optimally for the organisation's needs.

\section{WORKPLACE INCIVILITY AMONG HEALTH CARE WORKERS AND ITS HEALTH OUTCOMES: MENTAL HEALTH AND PHYSICAL COMPLAINTS}

${ }^{1}$ Kanami Tsuno*, ${ }^{2}$ Emiko Ando, ${ }^{3}$ Akiomi Inoue, ${ }^{4}$ Sumiko Kurioka, ${ }^{5}$ Norito Kawakami, ${ }^{1}$ Kazuhisa Miyashita. 'Wakayama Medical University, Wakayama, Japan; ${ }^{2}$ Osaka University, Osaka, Japan; ${ }^{3}$ Kitasato University, Kanagawa, Japan; ${ }^{4}$ Poole Gakuin University, Osaka, Japan; ${ }^{5}$ The University of Tokyo, Tokyo, Japan

\subsection{6/oemed-2018-ICOHabstracts. 1750}

Introduction For decades, workplace mistreatment such as psychological aggression, bullying, violence or interpersonal conflicts have received worldwide attention. On the other hand, health effects from milder mistreatment such as workplace incivility are not fully investigated. The aim of the study was therefore to investigate the association between workplace incivility and its mental and physical consequences.

Methods A cross-sectional study was conducted in various private health care centres in 2013 and 600 self-administered questionnaires were returned with sealed envelope (response rate: 91.2\%). Supervisor incivility, co-worker incivility, subordinate incivility and instigated incivility were measured by Straightforward Incivility Scale (SIS) (Leiter, 2012) and mental health such as vigour, anger-irritability, fatigue, anxiety, and depression and physical complaints were measured by the New Brief Job Stress Questionnaire (Inoue, et al., 2014). Hierarchical multiple regression analyses were conducted to estimate the effect of each incivility on mental health and physical complaints.

Result Average age of the participants was 45.4 (SD:11.5) years old and occupations included nurses (34.7\%), care workers $(25.0 \%)$, clerks $(18.0 \%)$, doctors/pharmacists $(5.1 \%)$, other co-medicals (17.1\%). The results of correlation analyses showed that all incivility variables had positive and significant associations with mental health except for vigour, which showed a negative association. Results of hierarchical multiple regression analyses showed that supervisor incivility had a significant main effect on depression, while co-worker incivility on fatigue and anxiety and instigated incivility on angerirritability.
Discussion Health effects from workplace incivility among health care workers may vary depending on who the perpetrators are. This contributes to understanding of mental health consequences from workplace incivility.

\section{GENDER DIFFERENCES IN TEACHERS' PERCEIVED PHYSICAL AND MENTAL STRAIN}

E Wischlitzki* ${ }^{*}$ W Fischmann, A Voss, N Amler, J Kiesel, H Drexler. Friedrich-Alexander University Erlangen-Nuremberg, Erlangen, Germany

10.1136/oemed-2018-ICOHabstracts. 1751

Introduction Teachers are facing various types of strain. Research of gender differences in teachers' health is scarce and not conclusive so far. The aim of this study was to assess gender differences in teachers' perceived physical and mental strain within the framework of a psychological risk assessment.

Methods A standardised questionnaire was handed out in 13 schools in Bavaria, Germany. Amongst other items, frequencies of diverse physical strain were assessed by a 6-point scale ranging from 'daily' to 'never/almost never'. The same scale served for assessing frequencies of mental strain. Gender differences were measured using Chi-square test.

Result 359 questionnaires were completed (return rate 45.4\%). 91 participants were male, 262 female (6 missing values). Main outcomes for physical strain in men were neck tension $(22.0 \%)$, sleeping disorders (16.5\%) and headache $(12.1 \%)$. Women also stated neck tension at most $(36.6 \%)$, followed by back pain (25.6\%) and sleeping disorders (16.8\%). Main outcomes for mental strain in men were feeling under time pressure $(58.2 \%)$ and exhausted/tired (49.5\%), followed by feeling tense and rushed $(42.9 \%$, each). Women also stated feeling under time pressure (54.6\%) and feeling exhausted/tired $(52.3 \%)$, followed by feeling rushed (38.9\%). Chi-square test didn't show significant gender differences in mental strain. Regarding physical strain, significant differences in men and women were found for neck tension $(\mathrm{p}=0.042)$ and back pain $(\mathrm{p}=0.025)$.

Conclusion Based on the sample, conclusions have to be drawn with care. Nevertheless, results suggest that there are gender differences in neck tension and back pain. In order to carry out sustainable interventions promoting teachers' health based on psychological risk assessments, possible influence by gender aspects should be taken into consideration or ruled out. However, further studies are needed to take profound action.

\section{INFLUENCE OF WORK AND PERSONAL-PROTECTIVE FACTORS ON COMMUTING SAFETY BEHAVIOURS: A GROWTH MODELLING APPROACH}

KA Burch*, JL Barnes-Farrell. University of Connecticut, Storrs, CT, USA

\subsection{6/oemed-2018-ICOHabstracts. 1752}

Introduction Research has shown that attitudes and behaviours developed in the work domain can spill over into non-work domains, however little attention has been paid to the impact 